Research Article

\title{
Effect of Polypropylene Fiber on Properties of Alkali-Activated Slag Mortar
}

\author{
Yangchen $X u$ iD, ${ }^{1,2}$ Haiming Chen $\mathbb{D}^{1,2}$ and Pengju Wang ${ }^{1,2}$ \\ ${ }^{1}$ School of Civil Engineering and Architecture, Anhui University of Science and Technology, Huainan 232001, China \\ ${ }^{2}$ Engineering Research Center of Underground Mine Construction, Ministry of Education, \\ Anhui University of Science and Technology, Huainan 232001, China \\ Correspondence should be addressed to Haiming Chen; chm818@163.com
}

Received 25 October 2019; Revised 7 December 2019; Accepted 16 December 2019; Published 6 January 2020

Academic Editor: Claudio Mazzotti

Copyright (c) 2020 Yangchen Xu et al. This is an open access article distributed under the Creative Commons Attribution License, which permits unrestricted use, distribution, and reproduction in any medium, provided the original work is properly cited.

\begin{abstract}
Alkali-activated slag (AAS) is becoming an increasingly popular building material due to its excellent engineering properties and low $\mathrm{CO}_{2}$ emissions, but its large shrinkage is an important reason to restrict its application and popularization. This work is aimed to study the possibility of inhibiting the shrinkage of AAS mortar by incorporating polypropylene fiber (PPF). For this, an experimental study was carried out to evaluate the effects of PPF content on setting time, fluidity, physical properties, mechanical properties, impact resistance, and microstructure of AAS mortar. The volume content of PPF is $0.05 \%, 0.1 \%, 0.15 \%$, and $0.2 \%$. The working, physical (porosity, water absorption, and bulk density), mechanical, shrinkage, and impact resistance properties of the AAS mortars were evaluated. The results show that incorporating PPF effectively reduces the shrinkage deformation of AAS mortar, significantly improves its impact resistance, enhances its toughness, and slightly improves its compressive strength in the later stage. At the same time, PPF delays the initial setting time of AAS mortar and reduces the fluidity, density, porosity, and water absorption of AAS mortar. SEM results show that the bridging effect of PPF between AAS mortars can inhibit the generation and propagation of cracks, improve the internal microstructure, and enhance the performance of AAS mortar.
\end{abstract}

\section{Introduction}

Cement is the largest manufactured product on Earth by mass [1]. The cement industry has grown steadily in the recent decades from 2.31 billion tons in 2005 to 4.13 billion tons in 2017, most of which are driven by the increasing demand from developing countries [2]. In China, the cement industrial production has reached 2.4 billion tons in 2017, $125 \%$ higher than 2005 , accounting for $58 \%$ of global cement output, and such situation is expected to continue in the next few decades [2]. However, cement production is a high-cost, energy-consuming, and pollution-intensive process [3-5]. Therefore, in order to reduce the greenhouse gas emissions and achieve sustainable environmental development, it is necessary to develop alternatives to Portland cement to reduce both $\mathrm{CO}_{2}$ emissions and energy consumption.

In the past decades, many studies have been carried out on alternative cementitious materials to replace Portland cement. For example, geopolymer cementitious materials (GPs) and alkali-activated cementitious materials (AAMs) are synthesized from industrial wastes, such as slag, fly ash, metakaolin, and others as raw materials with alkaline activator [6-14]. These cementitious materials have many advantages over ordinary Portland cement (OPC) in environmental protection (reducing $\mathrm{CO}_{2}$ emissions, saving energy, and waste utilization) [15-18], mechanical properties $[19,20]$, and durability [21-23]. Alkali-activated slag (AAS) is one of the most important cementitious materials which is made by slag and alkaline activator completely replacing the cement. Slag (also known as ground-granulated blast-furnace slag) is a byproduct of the blast furnace ironmaking process, and most of the slag is disposed at the landfill [24]. The slag may cause pollution to the air, so it is an ecological and environmental method to use it as cementitious material after alkali activation. Compared with OPC, AAS has 73\% lower greenhouse gas emissions [17], 
good mechanical properties [20], excellent chemical durability $[25,26]$, higher temperature resistance, and fire resistance $[27,28]$.

Nonetheless AAS cement, mortar and concretes exhibit a few shortcomings that hamper their standardization and more general use. One of the shortcomings is that AAS is susceptible to shrinkage and microcracks [29-32]. Several studies have revealed AAS concrete has higher drying shrinkage than OPC concrete [31,33-40]. For example, Palacios and Puertas [32] measured the drying shrinkage of waterglass-activated slag mortars. The results showed that the drying shrinkage of AAS mortars were about four times that of OPC mortars. Cartwright et al. [41] designed four AAS mortars to test their autogenous, chemical, and drying shrinkage; time of setting; and compressive strength. The results showed that AAS mortars showed higher autogenous and drying shrinkage than OPC mortar. Atiş et al. [34] measured the drying shrinkage of AAS mortar specimens activated by three different activators: liquid sodium silicate (LSS), sodium hydroxide (SH), and sodium carbonate (SC) and found that the drying shrinkage of AAS mortars activated by LSS and SH had a high drying shrinkage, up to 6 and 3 times that of OPC mortar, respectively. Collins and Sanjayan [42] also observed the similar results. Therefore, how to effectively control the shrinkage deformation of AAS is the main problem to be solved.

OPC mortar is one of most widely used building materials, but it is prone to drying and cracking [43]. Recently, researchers have shown an increased interest in filling fibers (steel fiber, basalt fiber, glass fiber, carbon fiber, polyacrylonitrile fiber, polypropylene fiber, etc.) into OPC mortar or concrete to reduce the shrinkage deformation and have made a lot of progress [44-46]. Similarly, adding fibers into AAS mortar can effectively reduce its shrinkage deformation. For example, Aydın and Baradan [47] investigated the effects of length and volume fraction of steel fibers on the mechanical properties and drying shrinkage behavior of steel fiber reinforced alkali-activated slag/silica fume (AASS) mortars. The results showed that the mechanical performance of AASS mortars was significantly better than OPC control mortar, and the drying shrinkage of AASS mortars decreased with the increasing fiber dosage. Vilaplana et al. [48] concluded that carbon fibers (CF) can be a convenient addition to control the drying shrinkage of AAS composites. Puertas et al. [49] found that alkali-resistant glass fiber can significantly reduce the drying shrinkage of AAS mortars (over 20\%).

Polypropylene fiber (PPF) is the most common synthetic fiber and widely used as a reinforcing material for ordinary Portland cement-based materials due to its high toughness and durability. Most studies have only been carried out focusing on the effect of different types of fibers on drying shrinkage of AAS mortar, and little attention has been paid to the effect of PPF on shrinkage of AAS mortar [47-49]. Therefore, the effects of PPF content (volume fraction from 0 to $0.2 \%$ ) on the physical, mechanical, shrinkage, impact resistance, and microstructure of AAS mortar were studied in this paper. The results show that PPF can not only reduce the drying shrinkage of AAS mortar and improve the impact resistance of mortar but also slightly improve the strength of AAS mortar. It is proved that PPF is a promising reinforcement agent of AAS cementitious materials.

\section{Materials and Methods}

2.1. Materials Used. The materials used in this work were Ground-Granulated Blast-Furnace Slag (GGBFS), sodium hydroxide, sand, and polypropylene fiber (PPF). The GGBFS was $\mathrm{S} 105$ grade blast-furnace slag with a density of $2800 \mathrm{~kg} /$ $\mathrm{m}^{3}$ and a Brunauer, Emmett, and Teller (BET) area of $1.535 \mathrm{~m}^{2} / \mathrm{g}$. The GGBFS was purchased from Fuyang Xinyuan Building Materials Co., Ltd. (China), and its chemical composition is shown in Table 1. Sodium hydroxide (purity over 96\%) was purchased from Yantai Shuangshuang Chemical Co., Ltd (China). The sodium hydroxide $(\mathrm{NaOH})$ solution was prepared by dissolving the pellets in water. GGBFS was activated with $7 \mathrm{M} \mathrm{NaOH}$ solutions. Activator solution was prepared one day before the casting of AAS mortar. PPF with length $9 \mathrm{~mm}$ was provided by Changsha Liqiang Building Material Co., Ltd (China). The main performance indicators of PPF are shown in Table 2. The macroscopic and microscopic shapes of PPF are shown in Figure 1. The sand was obtained from local sources with fineness modulus of 2.6 and apparent density of $2550 \mathrm{~kg} / \mathrm{m}^{3}$.

2.2. Mix Design and Processing of AAS Mortars. The design mix proportions of AAS mortars are shown in Table 3. The activator/cementitious material ratio is kept constant at 0.5 . PPF was added into the mortars with the volume content of $0.05 \%, 0.1 \%, 0.15 \%$, and $0.2 \%$. The preparation process of AAS mortars was similar to that of OPC mortars. Brief procedure for AAS mortars processing is as follows. (1) Prepare some clean rectangular molds of $40 \mathrm{~mm} \times 40 \mathrm{~mm} \times 160 \mathrm{~mm}$ and $25 \mathrm{~mm} \times 25 \mathrm{~mm} \times 280 \mathrm{~mm}$ and cylindrical molds with a diameter of $50 \mathrm{~mm}$ and a height of $100 \mathrm{~mm}$ before mixing the AAS mortars. Coat the inner surfaces of the molds evenly with a layer of engine oil as a release agent. At the same time, clean the mixer, remove excess water after cleaning, and keep a certain humidity inside the mixer. (2) Put rubbed PPF into the activator solutions and mix them fully to make the suspension uniform to overcome the disadvantage of poor dispersion of the PPF. (3) Pour the GGBFS and sand into the mixing pot and mix for $2 \mathrm{~min}$. (4) Add suspension into the mixing pot slowly and mix for additional $3 \mathrm{~min}$. (5) Pour the mixed AAS mortars into previously prepared molds and vibrate on the vibration table to remove bubbles.

2.3. Fluidity Test. The fluidity of AAS mortar specimens was measured in accordance with ASTM C1437-15 [50]. Place a layer of mortar about $25 \mathrm{~mm}$ in thickness in the flow mold and tamp 20 times with tamper. Fill the mold with mortar and tamp as specified for the first layer. Lift the mold away from mortar $1 \mathrm{~min}$ after completing the mixing operation. Immediately drop the table 25 times in $15 \mathrm{~s}$. The diameters of the spread mortar in two orthogonal directions were 
TABLE 1: The main chemical composition of the GGBFS.

\begin{tabular}{lcccccccc}
\hline Compounds & $\mathrm{CaO}$ & $\mathrm{SiO}_{2}$ & $\mathrm{Al}_{2} \mathrm{O}_{3}$ & $\mathrm{MgO}$ & $\mathrm{SO}_{3}$ & $\mathrm{Fe}_{2} \mathrm{O}_{3}$ & $\mathrm{TiO}_{2}$ & $\mathrm{~K}_{2} \mathrm{O}$ \\
\hline Percentage (\%) & 43.7 & 26.5 & 18.2 & 4.9 & 2.7 & 1.0 & 1.0 & 0.8 \\
\hline
\end{tabular}

TABLE 2: The main performance indicators of PPF.

\begin{tabular}{lccc}
\hline Performance indicator & Indicator data & Performance indicator & Indicator data \\
\hline Fiber type & Bundle monofilament & Resistance to acid and alkali & Extremely high \\
Density $\left(\mathrm{g} / \mathrm{cm}^{3}\right)$ & 0.91 & Thermal conductivity & Extremely low \\
Tensile strength $(\mathrm{MPa})$ & $>486$ & Resistance to low temperature & Strong \\
Elastic modulus $(\mathrm{GPa})$ & $>4.8$ & Water absorption & No \\
Diameter $(\mu \mathrm{m})$ & $18 \sim 48$ & Tensile limit & $>15 \%$ \\
\hline
\end{tabular}

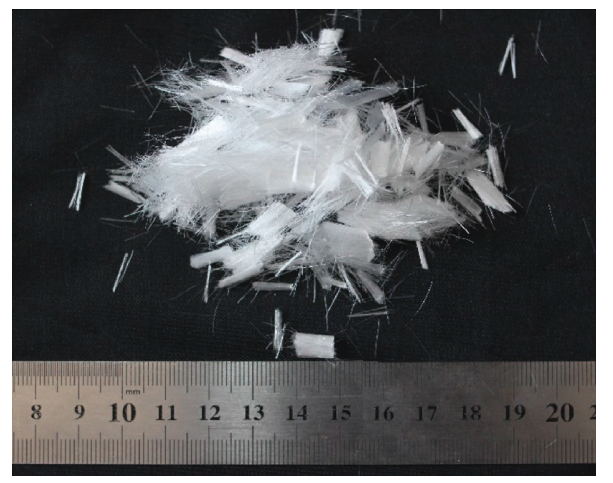

(a)

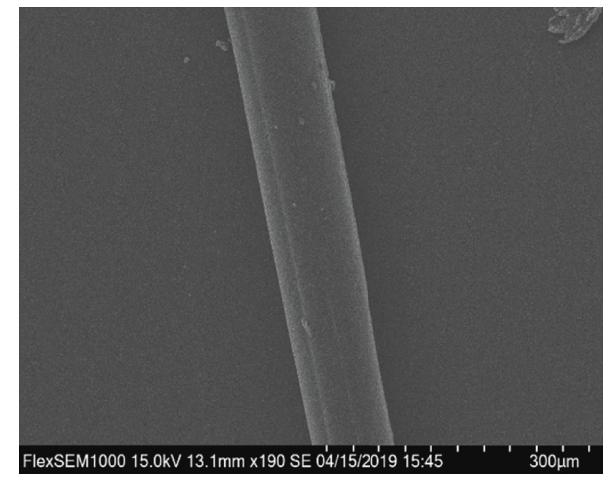

(b)

FIgURE 1: PPF with length $9 \mathrm{~mm}$. (a): Shape and dimension of PPF. (b): SEM picture of a single PPF.

TABLE 3: The mix proportions of the AAS mortars.

\begin{tabular}{|c|c|c|c|c|c|}
\hline \multirow{2}{*}{ Specimens } & \multicolumn{4}{|c|}{ Mix proportion $(\mathrm{g} / \mathrm{kg})$} & \multirow{2}{*}{$\begin{array}{c}\text { Volume } \\
\text { content (\%) }\end{array}$} \\
\hline & GGBFS & Sand & Activator & PPF & \\
\hline Control & 367 & 450 & 183 & 0 & 0 \\
\hline $\mathrm{P} 1$ & 367 & 450 & 183 & 0.156 & 0.05 \\
\hline $\mathrm{P} 2$ & 367 & 450 & 183 & 0.312 & 0.1 \\
\hline P3 & 367 & 450 & 183 & 0.468 & 0.15 \\
\hline $\mathrm{P} 4$ & 367 & 450 & 183 & 0.624 & 0.2 \\
\hline
\end{tabular}

measured, and the average diameter was reported as the fluidity of each group.

2.4. Setting Time Test. In accordance with ASTM C191-19 [51], the setting time of AAS mortar specimens were measured. AAS paste specimens were prepared by using Table 3 mix proportions. The specimens were placed in a humidity curing box with temperature of $(23 \pm 2)^{\circ} \mathrm{C}$ and relative humidity of more than $95 \%$. The penetration of Vicat needle was measured every 5 minutes.

2.5. Physical Properties Test. The values of apparent porosity, water absorption, and bulk density were determined by Archimedes method in accordance with ASTM C20-00 [52] at day 28. In this test, there are 15 specimens in total and 3 specimens in a group. The dry weight $D$, suspended weight $S$, and saturated weight $W$ of AAS mortar specimens were measured. Brief procedure for the physical properties test of mortar specimens was as follows: (1) dry the test mortar specimens in an oven at $105^{\circ} \mathrm{C}$ to constant weight and weigh the dry weight $D$, (2) place the test mortar specimens in distilled water and boil for 2 hours and weigh the suspended weight $S$ of each test specimen after boiling and cooling for a minimum of 12 hours and while suspended in water, and (3) blot each specimen lightly with a moistened smooth linen or cotton cloth to remove all drops of water from the surface and determine the saturated weight $W$. The apparent porosity $P$, the water absorption $A$, and bulk density $B$ were, respectively, calculated according to formulas (1) (3).

(1) Apparent porosity:

$$
P=\frac{W-D}{W-S} \times 100 \%
$$

(2) Water absorption:

$$
A=\frac{W-D}{D} \times 100 \%
$$

(3) Bulk density:

$$
B=\frac{D}{W-S} .
$$


2.6. Compressive Strength Test. The compressive strength of AAS mortar specimens was determined in accordance with ASTM C349-18 [53] by molding 45 prism specimens with a dimension of $40 \mathrm{~mm} \times 40 \mathrm{~mm} \times 160 \mathrm{~mm}$. A compression cap was used to ensure the compressed area of mortars of $40 \mathrm{~mm} \times 40 \mathrm{~mm}$. The mortar specimens were removed from the molds after curing for $24 \mathrm{~h}$ in a standard curing box with temperature of $(23 \pm 1)^{\circ} \mathrm{C}$ and relative humidity of more than $95 \%$. Then immerse the specimens in saturated lime water for $3 \mathrm{~d}, 7 \mathrm{~d}$ or $28 \mathrm{~d}$. Each group contained triplicate samples, and the average results were reported.

2.7. Drying Shrinkage Test. In accordance with ASTM C59618 [54], the drying shrinkage of AAS mortar specimens with $25 \mathrm{~mm} \times 25 \mathrm{~mm} \times 285 \mathrm{~mm}$ was determined. In this test, there are 15 specimens in total and 3 specimens in a group. Moist cure the specimens in the molds in the standard curing box for $24 \mathrm{~h}$. Then, remove the specimens from the molds and cure in lime-saturated water for $48 \mathrm{~h}$. At the age of $72 \mathrm{~h}$, remove the specimens from water, wipe with damp cloth, and immediately obtain the initial length for each specimen. Then, place the specimens in air storage with temperature of $(23 \pm 1)^{\circ} \mathrm{C}$ and relative humidity of $(50 \pm 3) \%$. Obtain a length comparator reading for each specimen after $1,2,3,4,5,6,7,14,21,28,42$, and $56 \mathrm{~d}$ of air storage. Three specimens were made, and the average results were reported. Drying shrinkage is calculated by the following equation:

$$
\varepsilon_{\text {drying }}=\frac{L(t)-L\left(t_{0}\right)}{L\left(t_{0}\right)} \times 10^{6} \mu \mathrm{m} / \mathrm{m},
$$

where $L(t)$ is the length of the specimen at the measuring time and $L\left(t_{0}\right)$ is the initial length of the specimen at the age of $72 \mathrm{~h}$.

2.8. Impact Performance Test. The impact uniaxial compression of fiber-modified AAS mortars was carried out using the $\Phi 50 \mathrm{~mm}$ variable cross section SHPB test system in the impact dynamics laboratory of Anhui University of Science and Technology. The sketch of SHPB experimental device is shown in Figure 2. A striker bar with a length of $600 \mathrm{~mm}$ and a diameter of $37 \mathrm{~mm}$ is used in the test. The lengths of the incident bar and the transmission bar are $2400 \mathrm{~mm}$ and $1200 \mathrm{~mm}$, respectively, and the diameter is $50 \mathrm{~mm}$. The bar are made of alloy steel with a density of $7800 \mathrm{~kg} / \mathrm{m}^{3}$, an elastic modulus of $210 \mathrm{GPa}$, a longitudinal wave velocity of $5190 \mathrm{~m} / \mathrm{s}$, and an air pressure of $0.3 \mathrm{MPa}$. The strain rate $\dot{\varepsilon}_{\mathrm{s}}(t)$, strain $e_{t}(t)$, and stress $s_{\mathrm{s}}(t)$ were calculated using the three-wave method [55-57]. The formulas are as follows:

$$
\begin{aligned}
& \dot{\varepsilon}_{\mathrm{s}}(t)=\frac{C_{0}}{L_{\mathrm{s}}}\left[\varepsilon_{t}(t)+\varepsilon_{\mathrm{r}}(t)-\varepsilon_{i}(t)\right], \\
& \varepsilon_{t}(t)=\frac{C_{0}}{L_{\mathrm{s}}} \int_{0}^{t}\left[\varepsilon_{t}(t)+\varepsilon_{\mathrm{r}}(t)-\varepsilon_{i}(t)\right] \mathrm{d} \tau, \\
& \sigma_{\mathrm{s}}(t)=\frac{S_{\mathrm{B}} E}{2 S_{\mathrm{s}}}\left[\varepsilon_{t}(t)+\varepsilon_{\mathrm{r}}(t)+\varepsilon_{i}(t)\right],
\end{aligned}
$$

where $S_{\mathrm{B}}$ and $S_{\mathrm{S}}$ are the elastic bars' cross-sectional area $\left(\mathrm{mm}^{2}\right)$ and the AAS mortar specimens cross-sectional area $\left(\mathrm{mm}^{2}\right) ; E$ and $C_{0}$ are the elastic bars' Young's modulus (GPa) and longitudinal wave velocity $(\mathrm{m} / \mathrm{s}) ; L_{\mathrm{S}}$ is the AAS mortar specimens' length $(\mathrm{mm}) ; \varepsilon_{i}(t), \varepsilon_{\mathrm{r}}(t)$, and $\varepsilon_{t}(t)$ are the captured strains of the tested AAS mortar specimens; $t$ is the stress wave duration.

Preparation of specimens: the AAS mortar specimens with diameter of $50 \mathrm{~mm}$ and height of $100 \mathrm{~mm}$ were made. After $28 \mathrm{~d}$ curing age, the specimens were cut and polished. The size of the specimens is $\Phi 50 \mathrm{~mm} \times 25 \mathrm{~mm}$. The nonparallelism of the end faces of the specimen is controlled within $0.02 \mathrm{~mm}$. Considering the discreteness of the test, there are 9 specimens in each group, 45 specimens in total. The results with large differences are discarded, and the average results are reported. Before the test, in order to eliminate the end friction effect, Vaseline was used to coat both ends of the specimen and the elastic bar. During the test, keep the specimen in coaxial with the elastic bar.

2.9. Microscopic Test. After $28 \mathrm{~d}$ curing age, crush the AAS mortar specimens into small pieces with a size of about $8 \mathrm{~mm} \times 8 \mathrm{~mm} \times 5 \mathrm{~mm}$, polish them by a polishing machine, and then dry them in a vacuum drying oven for 48 hours. Fix the dried AAS mortar pieces on a circular platform with a diameter of about $5 \mathrm{~cm}$ with double-sided adhesive tape and apply a proper amount of conductive tape to both sides of the mortar pieces and then remove their surface debris with the ear wash balls. Then, spray the mortar pieces containing paste and PPF with metal coating by magnetron sputtering in magnetron ion diffractometer (MSP-2S) for 120 seconds on the front and 30 seconds on the side. Finally, the microstructures were studied by scanning electron microscopy (HITACHI S3400). In this experiment, the specimens were placed in the center of the scanning electron microscope, and the bonding interface between the PPF and the AAS paste was observed.

All parameters above are explained with mean and standard deviation (SD) values.

\section{Results and Discussion}

3.1. Fluidity and Setting Time. Figure 3 shows the effect of the PPF content on the fluidity of AAS mortars. The fluidity of pure AAS mortar (without PPF) is relatively high. The fluidity of the AAS mortar decreased with the increase of the content of PPF. Compared to control mortar, the fluidity of P1, P2, P3, and P4 groups decreased by $0.52 \%, 1.29 \%, 2.32 \%$, and $4.12 \%$, respectively. The decrease in fluidity of AAS mortars can be attributed to the network spaces formed by the random distribution of PPF in the interior of AAS mortars. These network spaces often encapsulate AAS mortar clusters, which hinder the free flow of AAS mortar and reduce the fluidity of mortar. With the increase of the content of PPF, more and more network spaces will be formed and the fluidity of mortars will be lower [58]. On the other hand, addition of PPF offers higher shear resistance to flow which results in a decrease of fluidity [59]. The research 


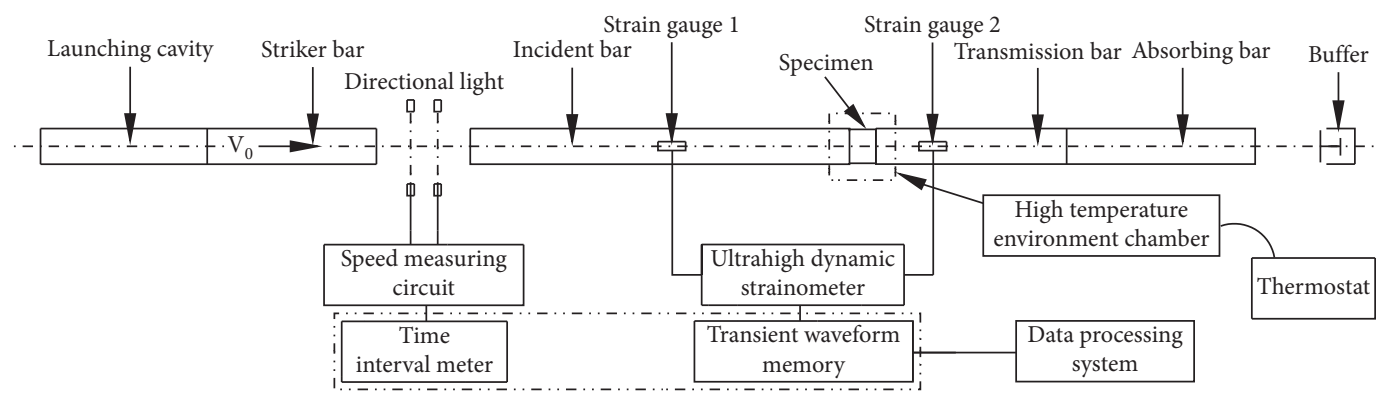

FIgURE 2: Sketch of the SHPB experimental device.

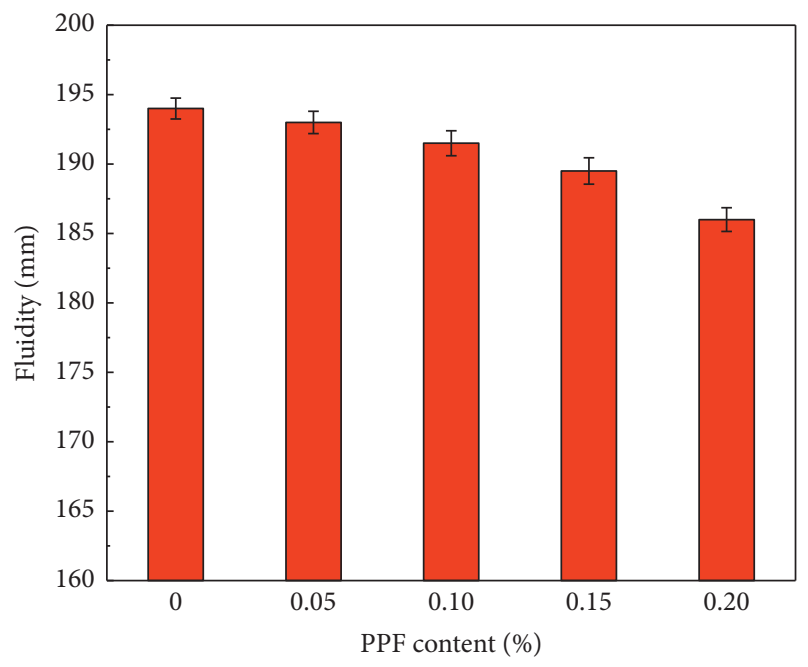

FIGURE 3: Evolution of the fluidity of AAS mortars as function of PPF content. The error bars represent the standard deviation of three test specimens.

results of Zhang et al. [60] showed that the fluidity of geopolymer gradually decreased with the increase of the content of PPF, which is consistent with the results of this study.

Figure 4 shows the setting time of AAS mortar with different contents of PPF. The addition of PPF delayed the initial setting time of AAS mortar and reduced the interval between the initial setting time and the final setting time of AAS mortar while there was a little effect of PPF on the final setting time. For example, the control group reached initial solidification between 20 and 25 minutes, the P1, P2, and P3 groups reached initial solidification between 25 and 30 minutes, and the $\mathrm{P} 4$ group reached initial solidification between 30 and 35 minutes. Nearly all the specimens in each group reached final solidification between 60 and 65 minutes. The setting time of AAS mortars increased with the increase of the content of PPF. This may be due to the hydrophobicity of PPF, which forms a barrier between water and cement particles which reduces the hydration speed of cement and delays the initial setting time of AAS mortars. Ranjbar et al. [59] got the similar results that the incorporation of polypropylene fiber delays the initial and final setting time of geopolymer composite.

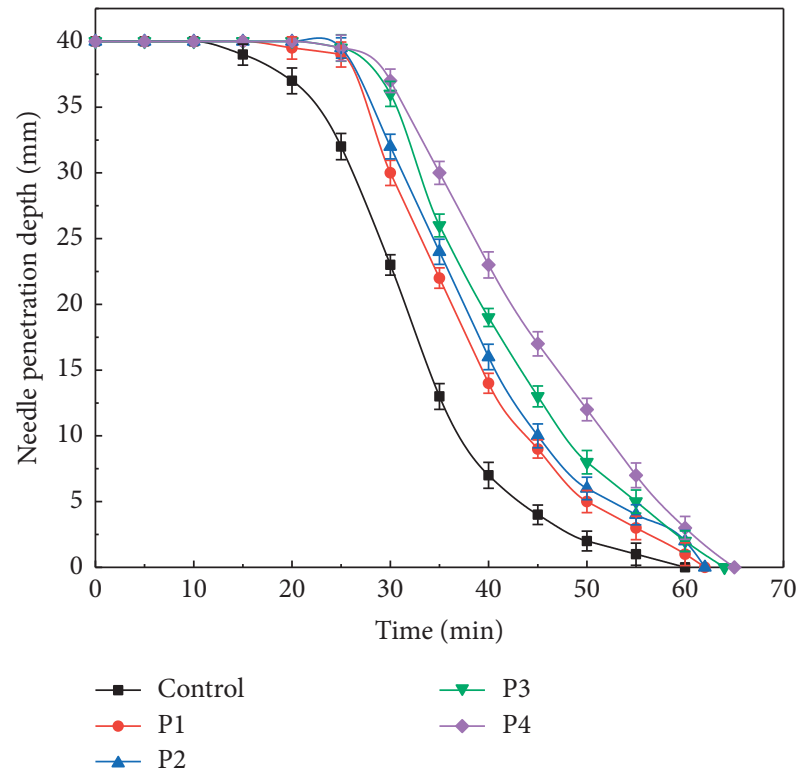

Figure 4: Evolution of the setting time of AAS mortars as function of PPF content. The error bars represent the standard deviation of three test specimens.

3.2. Physical Properties. The effect of the PPF content on physical properties (apparent porosity, water absorption, and bulk density) of the AAS mortars after $28 \mathrm{~d}$ curing age is shown in Figure 5. The apparent porosity, water absorption, and bulk density have decreased considerably for all mortar specimens with the increase of the content of PPF. Compared with the control mortar, the apparent porosity of P1, P2, P3, and P4 decreased by $1.44 \%, 2.65 \%, 3.20 \%$, and $4.74 \%$, respectively, at $28 \mathrm{~d}$. Different authors attribute the decrease in porosities of mortar to the filling effect of the microfibers. The higher the addition of PPF, the lower the porosity, because the internal pores (due to the filling effect) and the capillary pores (generated by the evaporation of water) are reduced [46]. Compared with the control group, the water absorption of P1, P2, $\mathrm{P} 3$, and $\mathrm{P} 4$ groups decreased by $1.48 \%, 2.94 \%, 4.49 \%$, and $5.34 \%$, respectively, at $28 \mathrm{~d}$. The low water absorption values can be attributed to the decrease in porosity. The bulk density of AAS mortar decreased slightly with the increase of the content of PPF which is due to the low specific gravity of PPF compared with the AAS paste [61, 62]. This is consistent with the findings of Ranjbar et al. [59]. 


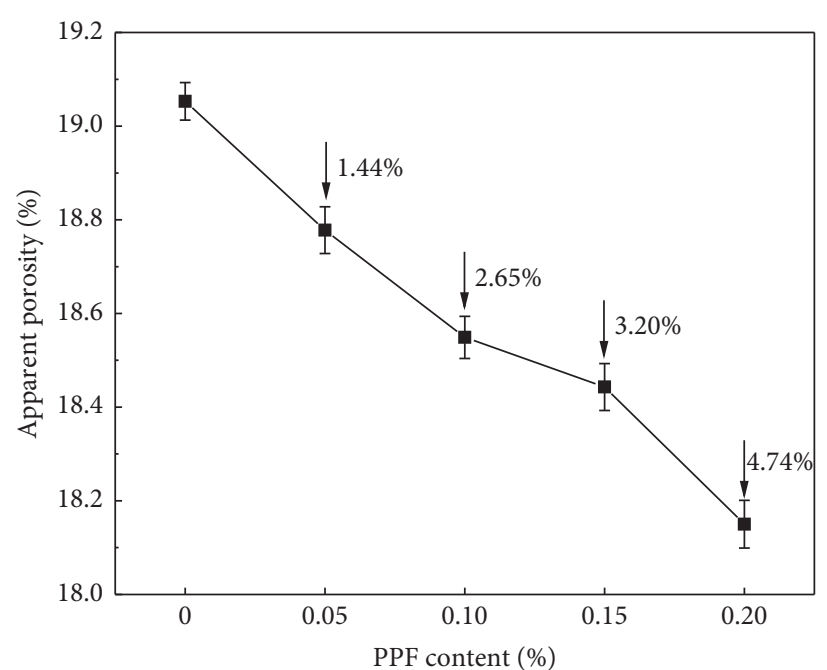

(a)

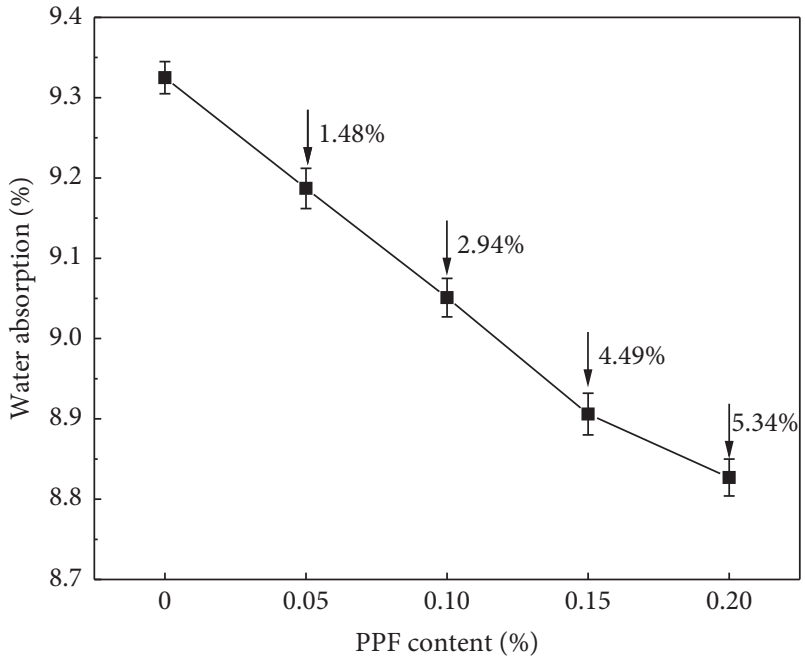

(b)

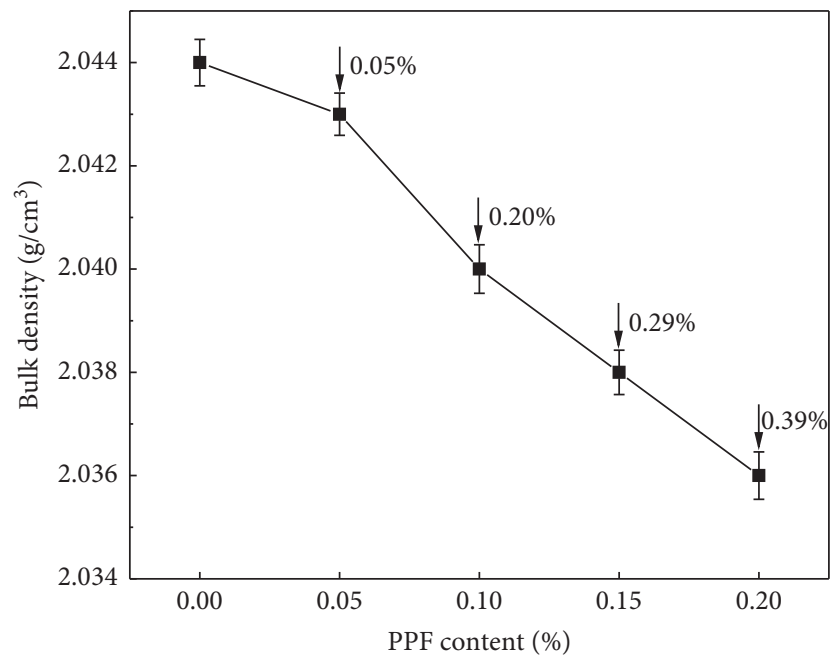

(c)

FIGURE 5: Effect of the PPF content on physical properties of the AAS mortar: (a) apparent porosity, (b) water absorption, and (c) bulk density. The error bars represent the standard deviation of three test specimens.

3.3. Mechanical Properties. The compressive strength results of AAS mortars with different PPF contents at $3 \mathrm{~d}, 7 \mathrm{~d}$, and $28 \mathrm{~d}$ are shown in Table 4 and Figure 6 . The compressive strength of AAS mortars at $3 \mathrm{~d}$ was less than the control mortar which can be explained by the hydrophobicity of PPF which reduces the hydration speed of cement. The compressive strength of AAS mortars at $7 \mathrm{~d}$ and $28 \mathrm{~d}$ is more than the control mortar. At $28 \mathrm{~d}$, the compressive strength of the specimens increased slightly with the increase of the PPF content. Compared with the control group, the compressive strength of P1, P2, P3, and P4 groups increased by $0.96 \%, 1.27 \%, 1.40 \%$, and $1.89 \%$, respectively. This is in accordance with the results of Guo and Pan [63]. The increase of compressive strength can be attributed to the ability of PPF to interrupt the initiation of microcracks, deviate their direction or avoid the extension of cracks, absorb tensions, decrease porosity, etc. $[46,64,65]$.
TABLE 4: Compressive strength of AAS mortars at 3, 7, and 28 days.

\begin{tabular}{lcccccc}
\hline \multirow{2}{*}{ Samples } & \multicolumn{5}{c}{ Compressive strength (MPa) } \\
& 3d & IR (\%) & 7 d & IR (\%) & 28 d & IR (\%) \\
\hline Control & 20.44 & & 23.50 & & 32.24 & \\
P1 & 19.64 & -3.91 & 23.68 & 0.77 & 32.55 & 0.96 \\
P2 & 19.95 & -2.40 & 24.25 & 3.19 & 32.65 & 1.27 \\
P3 & 19.75 & -3.38 & 24.74 & 5.28 & 32.69 & 1.40 \\
P4 & 19.43 & -4.94 & 23.40 & -0.43 & 32.85 & 1.89 \\
\hline
\end{tabular}

Note. IR (improvement ratio) $(\%)=(($ strength of sample - strength of control sample)/strength of control sample) $\times 100 \%$.

3.4. Drying Shrinkage. Figure 7 shows the drying shrinkage of all mixtures over the recording period of 56 days. The drying shrinkage of AAS mortar specimens increased with time. As seen from Figure 7, the addition of PPF can effectively reduce the drying shrinkage of AAS mortars and the drying shrinkage of AAS mortars decreased with the 

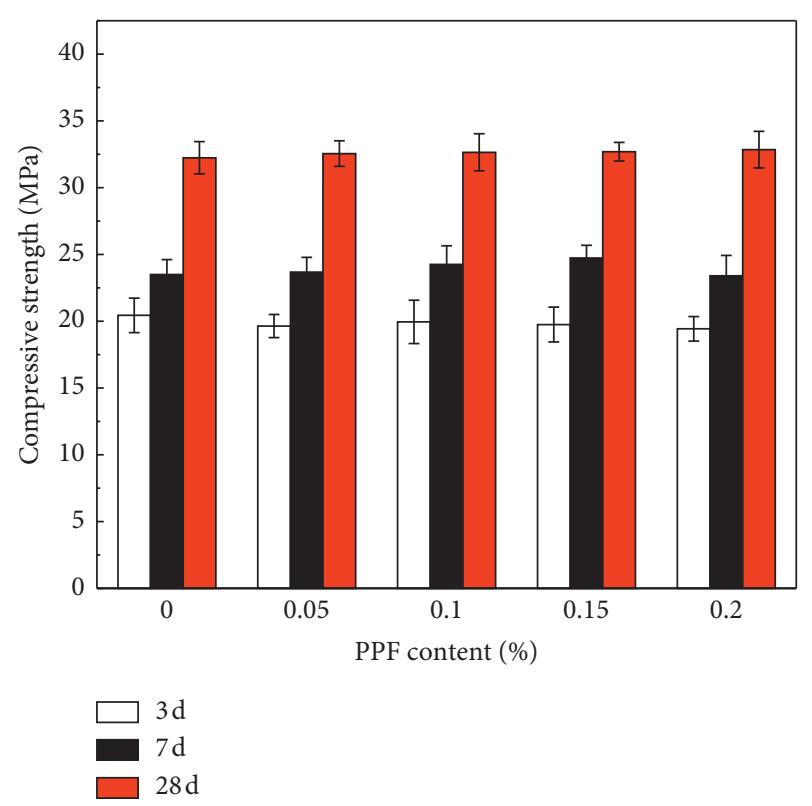

FIGURE 6: Evolution of the compressive strength of AAS mortars as function of PPF content. The error bars represent the standard deviation of three test specimens.

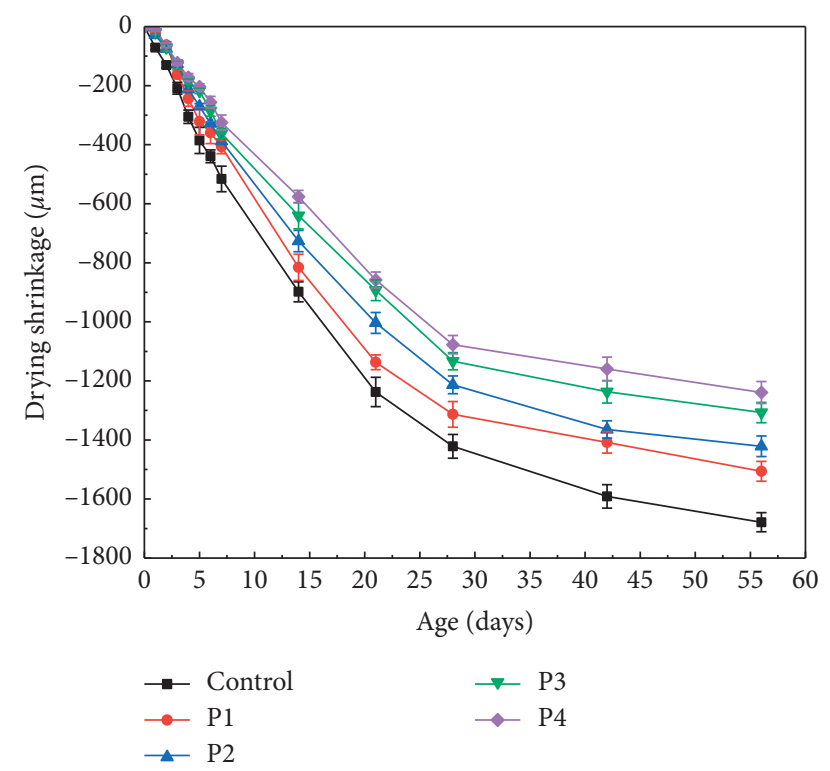

FIGURE 7: The drying shrinkage of AAS mortars vs. curing time. The error bars represent the standard deviation of three test specimens.

increase of the content of PPF. The best content of PPF is $0.2 \%$ to reduce the drying shrinkage of AAS mortars. This reduction might be attributed to the following effects. First, the tensile stress of the matrix is increased due to the clamping pressure and frictional bond between AAS matrix and PPF interface, and the existence of interfacial friction will counteract part of shrinkage energy, thus restraining the shrinkage of AAS mortar $[59,66]$. Moreover, PPF can bridge the cracks and inhibit their growth [5, 59]. Second, after adding PPF into AAS mortar, a large number of PPF evenly distributed in the mortar play the role of "supporting" aggregate, inhibit the sedimentation and segregation of water and mortar aggregate, reduce the water evolution on the surface of mortar, reduce the evaporation of water, and enhance the water-holding capacity of AAS mortar. At the same time, PPF on the surface of mortar slows down the evaporation rate of moisture and restrains the shrinkage of mortar $[44,67,68]$. Finally, the addition of PPF to AAS mortar improves the uniformity of AAS mortar and reduces the porosity of AAS mortar. Besides, the PPF can change the harmful macropore in AAS mortar into discontinuous and unconnected micropore, effectively block the passage of moisture escaping, and reduce the loss of moisture, thus reducing the shrinkage of AAS mortar [69]. This is in accordance with the findings of the previous studies that the addition of polypropylene fibers can reduce the drying shrinkage of geopolymer [60, 70, 71].

3.5. Impact Resistance Results. The stress-strain curves and related results of the AAS mortar specimens of each group are shown in Table 5 and Figure 8. The failure morphology of the specimens is shown in Figure 9. The results show that PPF can improve the dynamic compressive strength (the peak stress of stress-strain curves) of AAS mortars. Compared with the control mortar, the dynamic compressive strength of P1, P2, P3, and P4 groups increased by $6.40 \%$, $8.79 \%, 15.11 \%$, and $26.21 \%$, respectively. As seen Figure 9, the control mortar was more fragmented after impact damage, the P1 had less fragments and the P2, P3, and P4 groups specimens had better integrity with a few amount of fragments. After the incorporation of PPF, the peak strain of AAS mortars increased. Compared with the control mortar, the peak strain of P1, P2, P3, and P4 increased by $24.59 \%$, $65.04 \%, 107.32 \%$, and $154.07 \%$, respectively.

The dynamic compressive strength and peak strain of specimens studied alone cannot fully reflect the impact resistance of the AAS mortar specimens, so the toughness index is introduced to evaluate the impact resistance of specimens in this work [72]. Toughness is an important index to measure the dynamic performance materials, which reflects the deformation and the ability to absorb energy of materials. The area enclosed by the stress-strain curves and coordinate axis is used to indicate the amount of energy absorbed by specimens under impact load, and it is also an index to evaluate the toughness. The larger the area, the better the toughness [73]. Since the maximum strains of all specimens were more than 0.020 , the areas of stress-strain curve and coordinate axis in the strain range of $0-0.020$ were calculated in this experiment. Figure 10 shows the histogram of the toughness index of AAS mortar specimens. It can be seen from the Figure 10 that PPF can significantly improve the toughness of AAS mortar, and the toughness index of AAS mortar increases with the increase of the content of PPF. Compared with the control mortar, the toughness indexes of P1, P2, P3, and P4 groups increased by $20.27 \%$, $36.44 \%, 44.93 \%$, and $70.14 \%$, respectively. Therefore, $\mathrm{P} 4$ had the best impact resistance whose PPF content was $0.2 \%$. It is due to the mutual transmission of the stress-strain energy 
TABle 5: The results of impact experiment.

\begin{tabular}{lcccc}
\hline Samples & Average strain rate $\left(\mathrm{s}^{-1}\right)$ & Maximum dynamic stress $(\mathrm{MPa})$ & Peak strain & Failure characteristics \\
\hline Control & 69.70 & 38.77 & 0.00492 & Smash \\
P1 & 70.12 & 41.25 & 0.00613 & Partial fragments \\
P2 & 70.61 & 42.18 & 0.00812 & A small amount of fragments \\
P3 & 71.13 & 44.63 & 0.0102 & A small amount of fragments \\
P4 & 72.93 & 48.93 & 0.0125 & Complete \\
\hline
\end{tabular}

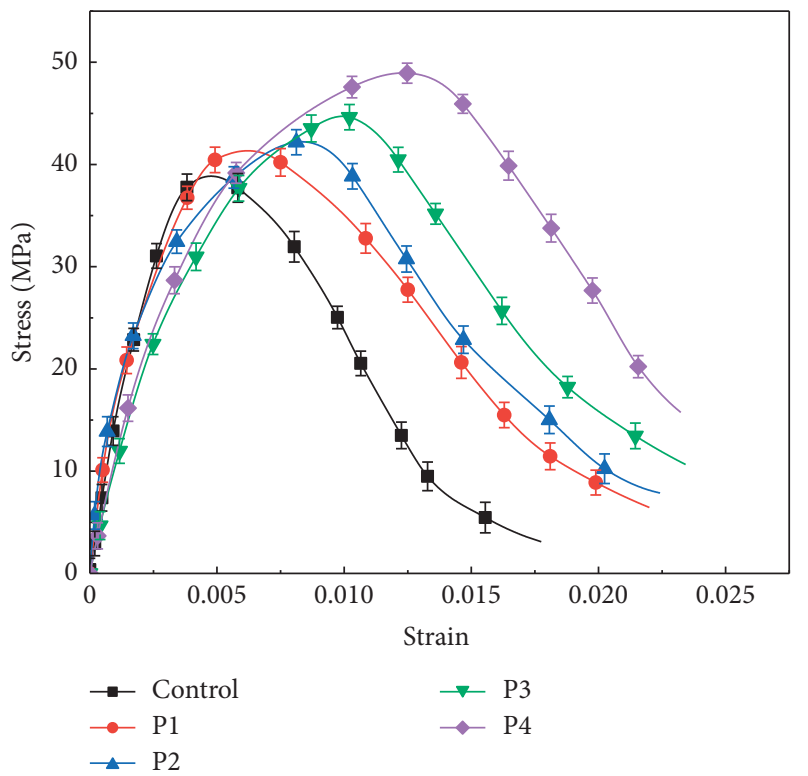

FIGURE 8: Stress-strain curves of AAS mortars. The error bars represent the standard deviation of nine test specimens.

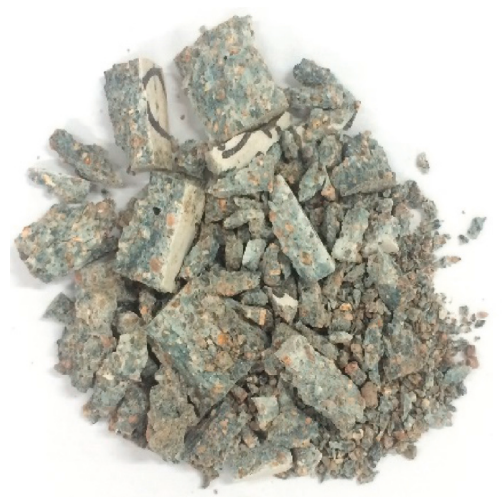

(a)

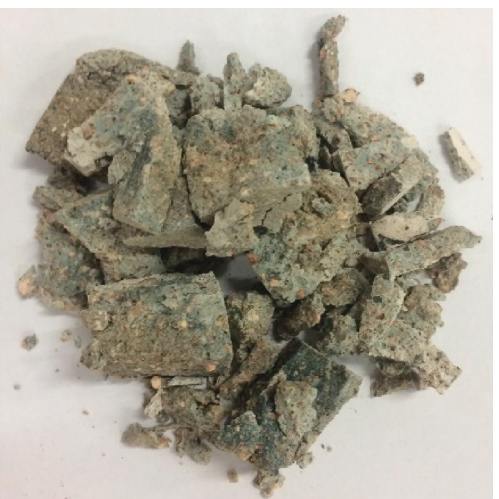

(b)

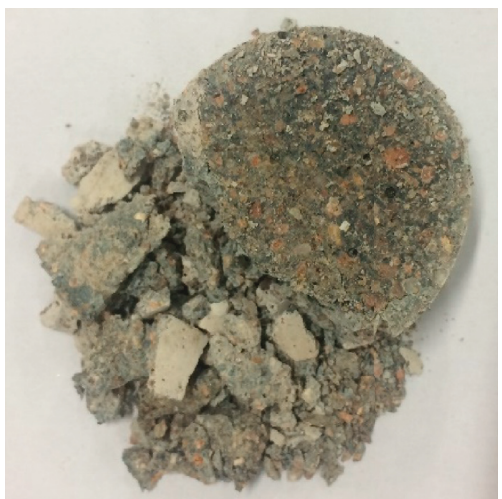

(c)

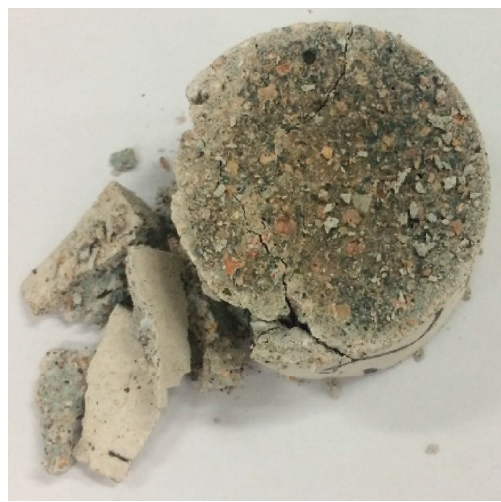

(d)

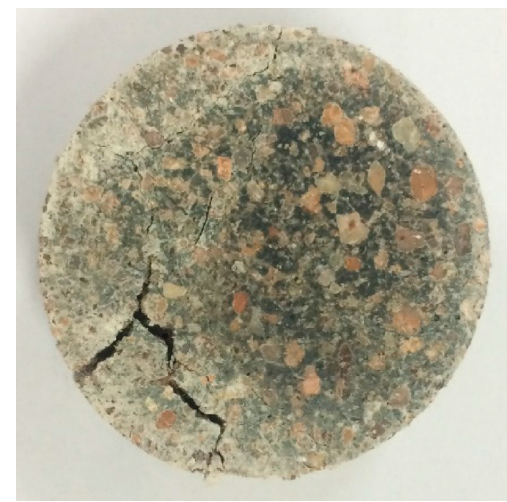

(e)

FIgURE 9: Effect of PPF content on failure morphology of AAS mortar specimens. (a) Control, (b) P1, (c) P2, (d) P3, and (e) P4. 


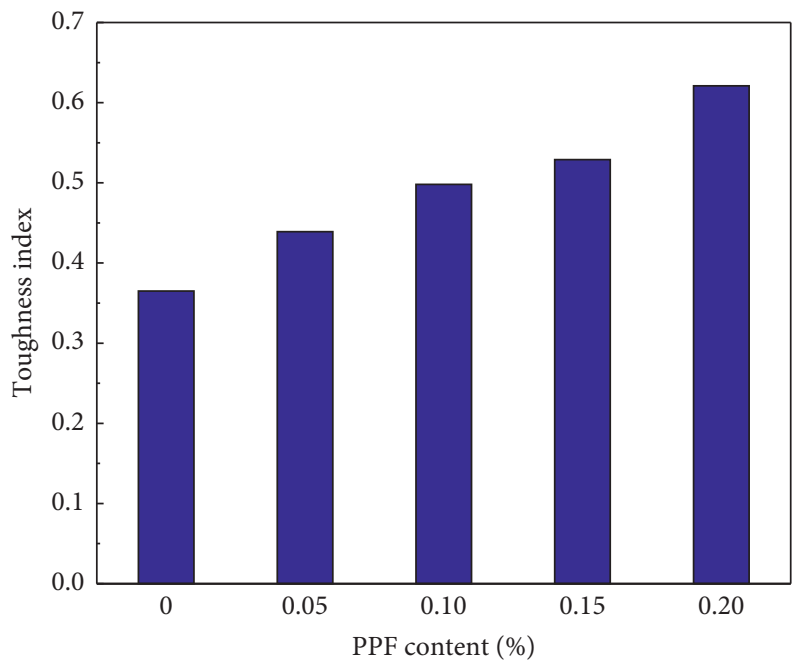

FIGURE 10: Evolution of the toughness index of AAS mortars as a function of PPF content.
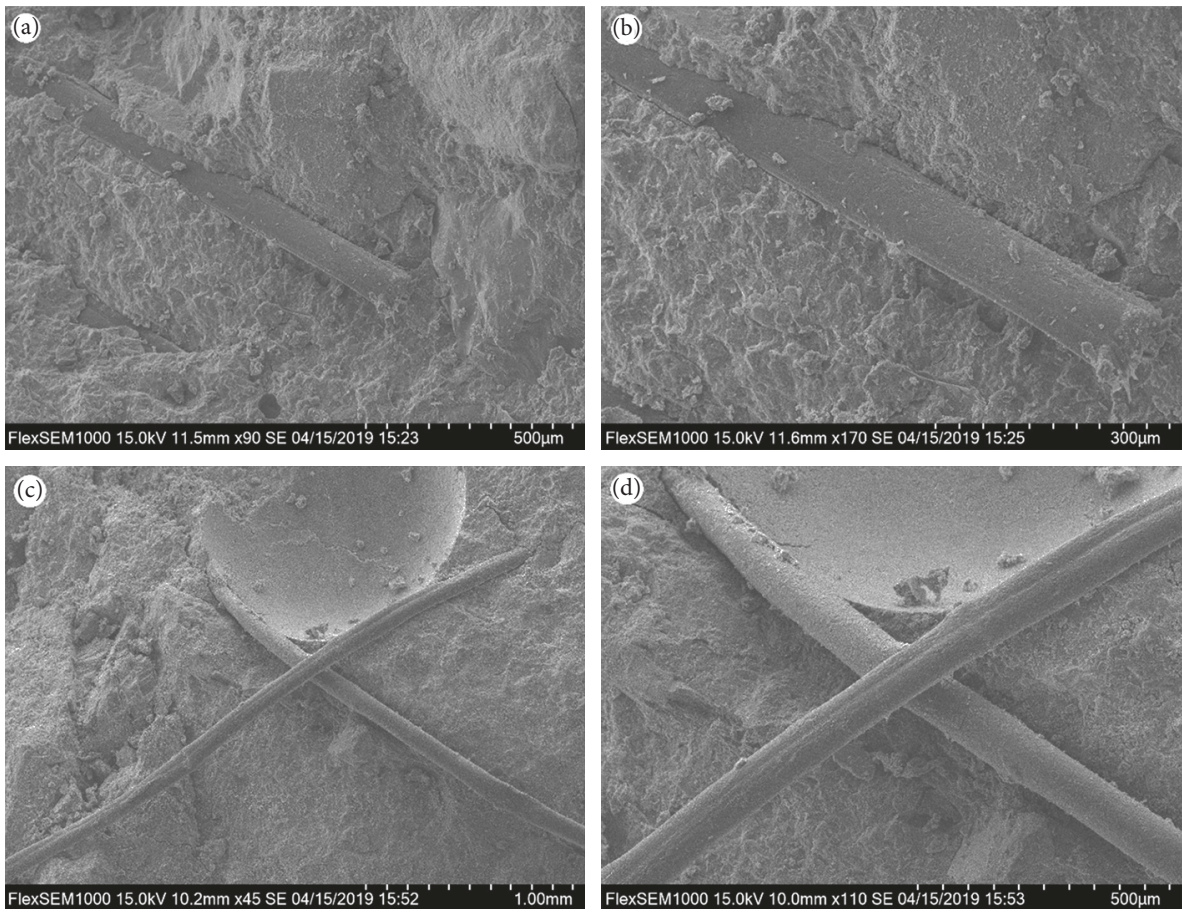

Figure 11: SEM pictures of P4 at 28-day. (a) Magnified 90 times. (b) Magnified 170 times. (c) Magnified 45 times. (d) Magnified 110 times.

between PPF and the matrix. The addition of PPF can inhibit the development of cracks. The PPF crossing the cracks or near the cracks tip can quickly transfer stress-strain energy to the surrounding cracks, which result in the prolongation of the failure process of the specimens. The addition of PPF increases the absorption energy of the AAS mortar specimens, thereby improving the impact resistance of the AAS mortars [74].

3.6. Microstructural Study. The SEM technology was applied to analyze the reinforcing mechanism of PPF on AAS mortars. The SEM of P4 group at curing age of 28 days is shown in Figure 11. The SEM specimens were chosen from the failed specimens of the compressive strength test. As seen from Figures 11(a) and 11(b), there is a good bonding between the PPF and AAS paste, which provides micromechanism explanation for the addition of PPF enhancing the compressive strength of AAS mortars [75]. In addition, no obvious deformation of the PPF surface can be observed, which indicates that PPF-reinforced AAS mortar has good durability and long-term properties [70]. It can be observed from Figures 11(c) and 11(d) that PPF can offer a bridging effect over the microcracks by embedding its two thrums in the matrix, which not only improves the mechanical properties of AAS mortar but also prevents the generation and propagation of microcracks, effectively absorb and 
dissipate the energy, and improve the crack resistance and impact resistance of the AAS mortar $[60,75]$.

\section{Conclusions}

This paper has presented the results of a systematic study on the effect of PPF on the physical, mechanical, impact resistance, and microstructure of AAS mortar. From the results obtained from this study, the following conclusions can be drawn:

The use of PPF in the AAS mortar causes a significant increase in the mechanical properties (the dynamic compressive strength, toughness of AAS mortar, and the impact resistance), enhances the durability properties such as porosity, water absorption, and resistance to water penetration, and reduces the drying shrinkage. Since PPF improved the properties of AAS mortar, the range of applications could expand significantly.

\section{Data Availability}

The data used to support the findings of this study are available from the corresponding author upon request.

\section{Conflicts of Interest}

The authors declare no conflicts of interest.

\section{Acknowledgments}

This work was supported by the National Natural Science Foundation of China (Project nos. 41440018, 41977236, and 41672278) and the National Natural Science Foundation of China Overseas and Hong Kong-Macao Scholar Cooperative Research Foundation (Project no. 51728201).

\section{References}

[1] K. L. Scrivener, V. M. John, and E. M. Gartner, "Eco-efficient cements: potential economically viable solutions for a low$\mathrm{CO}_{2}$ cement-based materials industry," Cement and Concrete Research, vol. 114, pp. 2-26, 2018.

[2] D. Song, L. Lin, and Y. Wu, "Extended exergy accounting for a typical cement industry in China," Energy, vol. 174, pp. 678-686, 2019.

[3] J. Wei, K. Cen, and Y. Geng, "China's cement demand and $\mathrm{CO}_{2}$ emissions toward 2030: from the perspective of socioeconomic, technology and population," Environmental Science and Pollution Research, vol. 26, no. 7, pp. 6409-6423, 2019.

[4] K. Kermeli, O. Y. Edelenbosch, W. Crijns-Graus et al., "The scope for better industry representation in long-term energy models: modeling the cement industry," Applied Energy, vol. 240, pp. 964-985, 2019.

[5] A. M. Rashad, "The effect of polypropylene, polyvinyl-alcohol, carbon and glass fibres on geopolymers properties," Materials Science and Technology, vol. 35, no. 2, pp. 127-146, 2019.

[6] Q. Wan, F. Rao, S. Song et al., "Geopolymerization reaction, microstructure and simulation of metakaolin-based geopolymers at extended $\mathrm{Si} / \mathrm{Al}$ ratios," Cement and Concrete Composites, vol. 79, pp. 45-52, 2017.
[7] P. He, M. Wang, S. Fu et al., "Effects of $\mathrm{Si} / \mathrm{Al}$ ratio on the structure and properties of metakaolin based geopolymer," Ceramics International, vol. 42, no. 13, pp. 14416-14422, 2016.

[8] C. Li, H. Sun, and L. Li, "A review: the comparison between alkali-activated slag $(\mathrm{Si}+\mathrm{Ca})$ and metakaolin $(\mathrm{Si}+\mathrm{Al})$ cements," Cement and Concrete Research, vol. 40, no. 9, pp. 1341-1349, 2010.

[9] F. Pacheco-Torgal, Z. Abdollahnejad, A. F. Camões, M. Jamshidi, and Y. Ding, "Durability of alkali-activated binders: a clear advantage over Portland cement or an unproven issue?," Construction and Building Materials, vol. 30, pp. 400-405, 2012.

[10] I. Ozer and S. Soyer-Uzun, "Relations between the structural characteristics and compressive strength in metakaolin based geopolymers with different molar Si/Al ratios," Ceramics International, vol. 41, no. 8, pp. 10192-10198, 2015.

[11] P. Rovnaník, "Effect of curing temperature on the development of hard structure of metakaolin-based geopolymer," Construction and Building Materials, vol. 24, no. 7, pp. 1176-1183, 2010.

[12] D. Khale and R. Chaudhary, "Mechanism of geopolymerization and factors influencing its development: a review," Journal of Materials Science, vol. 42, no. 3, pp. 729-746, 2007.

[13] F. Pacheco-Torgal, J. Castro-Gomes, and S. Jalali, "Alkaliactivated binders: a review," Construction and Building Materials, vol. 22, no. 7, pp. 1305-1314, 2008.

[14] P. Duxson, J. L. Provis, G. C. Lukey, and J. S. J. van Deventer, "The role of inorganic polymer technology in the development of "green concrete"," Cement and Concrete Research, vol. 37, no. 12, pp. 1590-1597, 2007.

[15] G. Habert and C. Ouellet-Plamondon, "Recent update on the environmental impact of geopolymers," RILEM Technical Letters, vol. 1, pp. 17-23, 2016.

[16] M. C. G. Juenger, F. Winnefeld, J. L. Provis, and J. H. Ideker, "Advances in alternative cementitious binders," Cement and Concrete Research, vol. 41, no. 12, pp. 1232-1243, 2011.

[17] M. Jiang, X. Chen, F. Rajabipour, and C. T. Hendrickson, "Comparative life cycle assessment of conventional, glass powder, and alkali-activated slag concrete and mortar," Journal of Infrastructure Systems, vol. 20, no. 4, Article ID 04014020, 2014.

[18] R. Thomas, H. Ye, A. Radlińska, and S. Peethamparan, “Alkali-activated slag cement concrete: a closer look at a sustainable alternative to portland cement," Concrete International, vol. 38, no. 1, pp. 33-38, 2016.

[19] Y. Ding, J.-G. Dai, and C.-J. Shi, "Mechanical properties of alkali-activated concrete: a state-of-the-art review," Construction and Building Materials, vol. 127, pp. 68-79, 2016.

[20] S. Aydin and B. Baradan, "Effect of activator type and content on properties of alkali-activated slag mortars," Composites Part B: Engineering, vol. 57, pp. 166-172, 2014.

[21] M. Albitar, M. S. Mohamed Ali, P. Visintin, and M. Drechsler, "Durability evaluation of geopolymer and conventional concretes," Construction and Building Materials, vol. 136, pp. 374-385, 2017.

[22] H. J. Zhuang, H. Y. Zhang, and H. Xu, "Resistance of geopolymer mortar to acid and chloride attacks," Procedia Engineering, vol. 210, pp. 126-131, 2017.

[23] T. Bakharev, "Resistance of geopolymer materials to acid attack," Cement and Concrete Research, vol. 35, no. 4, pp. 658-670, 2005. 
[24] D. M. Roy, "Alkali-activated cements opportunities and challenges," Cement and Concrete Research, vol. 29, no. 2, pp. 249-254, 1999.

[25] T. Bakharev, J. G. Sanjayan, and Y.-B. Cheng, "Resistance of alkali-activated slag concrete to acid attack," Cement and Concrete Research, vol. 33, no. 10, pp. 1607-1611, 2003.

[26] T. Bakharev, J. G. Sanjayan, and Y.-B. Cheng, "Sulfate attack on alkali-activated slag concrete," Cement and Concrete Research, vol. 32, no. 2, pp. 211-216, 2002.

[27] W.-C. Wang, H.-Y. Wang, and M.-H. Lo, “The engineering properties of alkali-activated slag pastes exposed to high temperatures," Construction and Building Materials, vol. 68, pp. 409-415, 2014.

[28] K. Behfarnia and M. Shahbaz, "The effect of elevated temperature on the residual tensile strength and physical properties of the alkali-activated slag concrete," Journal of Building Engineering, vol. 20, pp. 442-454, 2018.

[29] F. Collins and J. G. Sanjayan, "Microcracking and strength development of alkali activated slag concrete," Cement and Concrete Composites, vol. 23, no. 4-5, pp. 345-352, 2001.

[30] A. A. M. Neto, M. A. Cincotto, and W. Repette, "Drying and autogenous shrinkage of pastes and mortars with activated slag cement," Cement and Concrete Research, vol. 38, no. 4, pp. 565-574, 2008.

[31] F. Collins and J. G. Sanjayan, "Cracking tendency of alkaliactivated slag concrete subjected to restrained shrinkage," Cement and Concrete Research, vol. 30, no. 5, pp. 791-798, 2000.

[32] M. Palacios and F. Puertas, "Effect of shrinkage-reducing admixtures on the properties of alkali-activated slag mortars and pastes," Cement and Concrete Research, vol. 37, no. 5, pp. 691-702, 2007.

[33] H. Ye, C. Cartwright, F. Rajabipour, and A. Radlińska, "Understanding the drying shrinkage performance of alkaliactivated slag mortars," Cement and Concrete Composites, vol. 76, pp. 13-24, 2017.

[34] C. D. Atiş, C. Bilim, Ö. Çelik, and O. Karahan, "Influence of activator on the strength and drying shrinkage of alkali-activated slag mortar," Construction and Building Materials, vol. 23, no. 1, pp. 548-555, 2009.

[35] H. Ye, C. Cartwright, F. Rajabipour, and A. Radlińska, "Effect of drying rate on shrinkage of alkali-activated slag cements," in Proceedings of the International Conference on Durability of Concrete Structures, pp. 254-261, Purdue University, West Lafayette, IN, USA, July 2014.

[36] M. Mastali, P. Kinnunen, A. Dalvand, R. Mohammadi Firouz, and M. Illikainen, "Drying shrinkage in alkali-activated binders-a critical review," Construction and Building Materials, vol. 190, pp. 533-550, 2018.

[37] H. Ye and A. Radlińska, "Shrinkage mitigation strategies in alkali-activated slag," Cement and Concrete Research, vol. 101, pp. 131-143, 2017.

[38] H. Ye and A. Radlińska, "Shrinkage mechanisms of alkaliactivated slag," Cement and Concrete Research, vol. 88, pp. 126-135, 2016.

[39] T. Bakharev, J. G. Sanjayan, and Y.-B. Cheng, "Alkali activation of Australian slag cements," Cement and Concrete Research, vol. 29, no. 1, pp. 113-120, 1999.

[40] N. K. Lee, J. G. Jang, and H. K. Lee, "Shrinkage characteristics of alkali-activated fly ash/slag paste and mortar at early ages," Cement and Concrete Composites, vol. 53, pp. 239-248, 2014.

[41] C. Cartwright, F. Rajabipour, and A. Radlińska, "Shrinkage characteristics of alkali-activated slag cements," Journal of
Materials in Civil Engineering, vol. 27, no. 7, p. B4014007, 2015.

[42] F. Collins and J. G. Sanjayan, "Effect of pore size distribution on drying shrinking of alkali-activated slag concrete," Cement and Concrete Research, vol. 30, no. 9, pp. 1401-1406, 2000.

[43] S. Zhao, G. Li, and Y. Wang, "Influence of polypropylene fibers and polymer emulsion on the dry-shrinkage crack of cement mortar," Journal of North University, vol. 33, pp. 612-616, 2012, in Chinese.

[44] L. Liu, P. Wang, and X. Yang, "Effect of polypropylene fiber on dry-shrinkage ratio of cement mortar," Journal of Building Materials and Structures, vol. 8, pp. 373-377, 2005, in Chinese.

[45] J. S. Lawler, D. Zampini, and S. P. Shah, "Microfiber and macrofiber hybrid fiber-reinforced concrete," Journal of Materials in Civil Engineering, vol. 17, no. 5, pp. 595-604, 2005.

[46] M. J. Chinchillas-Chinchillas, V. M. Orozco-Carmona, A. Gaxiola et al., "Evaluation of the mechanical properties, durability and drying shrinkage of the mortar reinforced with polyacrylonitrile microfibers," Construction and Building Materials, vol. 210, pp. 32-39, 2019.

[47] S. Aydin and B. Baradan, "The effect of fiber properties on high performance alkali-activated slag/silica fume mortars," Composites Part B: Engineering, vol. 45, no. 1, pp. 63-69, 2013.

[48] J. L. Vilaplana, F. J. Baeza, O. Galao, E. G. Alcocel, E. Zornoza, and P. Garcés, "Mechanical properties of alkali activated blast furnace slag pastes reinforced with carbon fibers," Construction and Building Materials, vol. 116, pp. 63-71, 2016.

[49] F. Puertas, A. Gil-Maroto, M. Palacios, and T. Amat, "Alkaliactivated slag mortars reinforced with ar glassfibre. Performance and properties," Materiales de Construcción, vol. 56, pp. 79-90, 2006.

[50] ASTM C1437-15, Standard Test Method for Flow of Hydraulic Cement Mortar, ASTM International, West Conshohocken, PA, USA, 2015.

[51] ASTM C191-19, Standard Test Methods for Time of Setting of Hydraulic Cement by Vicat Needle, ASTM International, West Conshohocken, PA, USA, 2019.

[52] ASTM C20-00, Standard Test Method for Apparent Porosity, Water Absorption, Apparent Specific Gravity, and Bulk Density of Burned Refractory Brick and Shapes by Boiling Water, ASTM International, West Conshohocken, PA, USA, 2015.

[53] ASTM C349-18, Standard Test Method for Compressive Strength of Hydraulic-Cement Mortars Using Portions of Prisms Broken in Flexure, ASTM International, West Conshohocken, PA, USA, 2018.

[54] ASTM C596-18, Standard Test Method for Drying Shrinkage of Mortar Containing Hydraulic Cement, ASTM International, West Conshohocken, PA, USA, 2018.

[55] W. Li, J. Xu, Y. Zhai, and Q. Li, "Mechanical properties of carbon fiber reinforced concrete under impact loading," China Civil Engineering Journal, vol. 42, pp. 24-30, 2009, in Chinese.

[56] M. Wang, H. Wang, and Q. Zong, "Analysis dynamic mechanical characteristics and fracture breaking characteristics of coal mine mudstone," Journal of Vibration and Shock, vol. 38, pp. 137-143, 2019, in Chinese.

[57] M. Chen, W. Chen, H. Zhong, D. Chi, Y. Wang, and M. Zhang, "Experimental study on dynamic compressive behaviour of recycled tyre polymer fibre reinforced concrete," Cement and Concrete Composites, vol. 98, pp. 95-112, 2019. 
[58] B. Zhao, Y. Liu, S. He, and Y. Zhang, "The effects of basalt fiber parameter on the fluidity of the cement mortar," Journal of Wuhan University of Technology, vol. 31, pp. 5-8, 2009, in Chinese.

[59] N. Ranjbar, M. Mehrali, A. Behnia et al., "A comprehensive study of the polypropylene fiber reinforced fly ash based geopolymer," PLoS One, vol. 11, Article ID e0147546, 2016.

[60] Z.-H. Zhang, X. Yao, H.-J. Zhu, S.-D. Hua, and Y. Chen, "Preparation and mechanical properties of polypropylene fiber reinforced calcined kaolin-fly ash based geopolymer," Journal of Central South University of Technology, vol. 16, no. 1, pp. 49-52, 2009.

[61] N. Ranjbar, S. Talebian, M. Mehrali, C. Kuenzel, H. S. Cornelis Metselaar, and M. Z. Jumaat, "Mechanisms of interfacial bond in steel and polypropylene fiber reinforced geopolymer composites," Composites Science and Technology, vol. 122, pp. 73-81, 2016.

[62] H. Chen, Y. Xu, D. Zhang, L. Huang, Y. Zhu, and L. Huang, "The influence of nano-SiO2 and recycled polypropylene plastic content on physical, mechanical, and shrinkage properties of mortar," Advances in Civil Engineering, vol. 2019, Article ID 6960216, 12 pages, 2019.

[63] X. Guo and X. Pan, "Mechanical properties and mechanisms of fiber reinforced fly ash-steel slag based geopolymer mortar," Construction and Building Materials, vol. 179, pp. 633$641,2018$.

[64] V. Afroughsabet and T. Ozbakkaloglu, "Mechanical and durability properties of high-strength concrete containing steel and polypropylene fibers," Construction and Building Materials, vol. 94, pp. 73-82, 2015.

[65] H. Yan, W. Sun, and H. Chen, "The effect of silica fume and steel fiber on the dynamic mechanical performance of highstrength concrete," Cement and Concrete Research, vol. 29, no. 3, pp. 423-426, 1999.

[66] H. Stang, "Significance of shrinkage-induced clamping pressure in fiber-matrix bonding in cementitious composite materials," Advanced Cement Based Materials, vol. 4, no. 3-4, pp. 106-115, 1996.

[67] Z. Yang, J. Guo, and C. Gao, "Effect of polypropylene fiber on properties of aeolian-sand mortar," Journal of the Chinese Ceramic Society, vol. 38, pp. 436-439, 2019, in Chinese.

[68] Y. Ma, B. Zhu, M. Tan, and K. Wu, "Effect of Y type polypropylene fiber on plastic shrinkage cracking of cement mortar," Materials and Structures, vol. 37, no. 2, pp. 92-95, 2004.

[69] S. Zhao, L. Wang, and C. Li, "Experimental study on dryshrinkage of polypropylene fiber reinforced dement mortar with machine-made sand," Journal of North China University of Water Resources and Electric Power, vol. 35, pp. 17-21, 2014, in Chinese.

[70] M. M. Al-mashhadani, O. Canpolat, Y. Aygörmez, M. Uysal, and S. Erdem, "Mechanical and microstructural characterization of fiber reinforced fly ash based geopolymer composites," Construction and Building Materials, vol. 167, pp. 505-513, 2018.

[71] Z. Abdollahnejad, Z. Zhang, H. Wang, and M. Mastali, "Comparative study on the drying shrinkage and mechanical properties of geopolymer foam concrete incorporating different dosages of fiber, sand and foam agents," in High Tech Concrete: Where Technology and Engineering Meet, D. Hordijk and M. Luković, Eds., pp. 42-48, Springer, Berlin, Germany, 2018.

[72] X. Liu, W. Ke, N. Liang, Q. Miao, P. Yang, and Z. Guo, "Study on the dynamic mech anical properties of concrete multi size polypropylene fiber based on SHPB test," International Materials Reviews, vol. 32, pp. 484-489, 2018, in Chinese.

[73] B. Wang, H. Zhang, and A. Xie, "Experimental study on impact toughness and microscopic interface of basalt fiber reinforced concrete," Journal of China Three Gorges University, vol. 38, pp. 55-59, 2016, in Chinese.

[74] S. Qin, "Study on dynamic mechanical properties of fiber cement mortar," Master thesis, Guangzhou University, Guangzhou, China, 2018, in Chinese.

[75] C. Jiang, H. Zhao, D. Chen, and W. Zhang, "Comparing and analyzing influence of basalt and polypropylene fiber on the cement mortar," Journal of the Chinese Ceramic Society, vol. 26, pp. 1084-1088, 2007, in Chinese. 


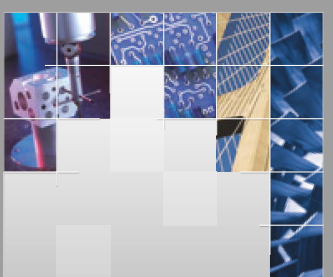

\section{Enfincering}
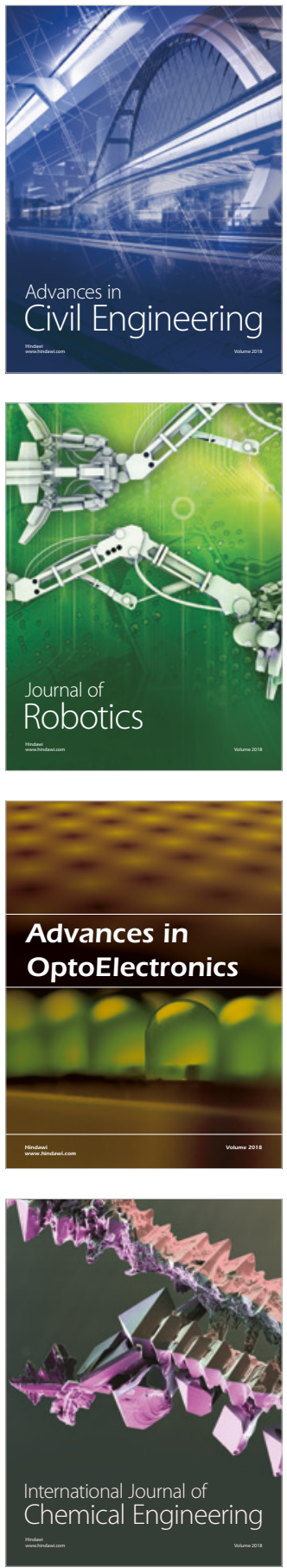

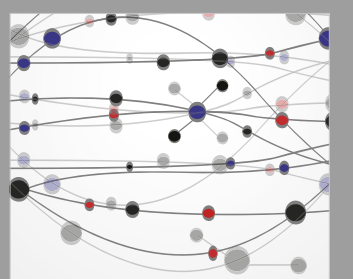

\section{Rotating \\ Machinery}

The Scientific World Journal

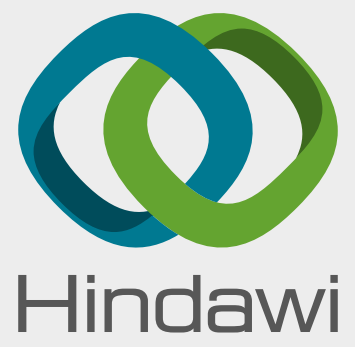

Submit your manuscripts at

www.hindawi.com
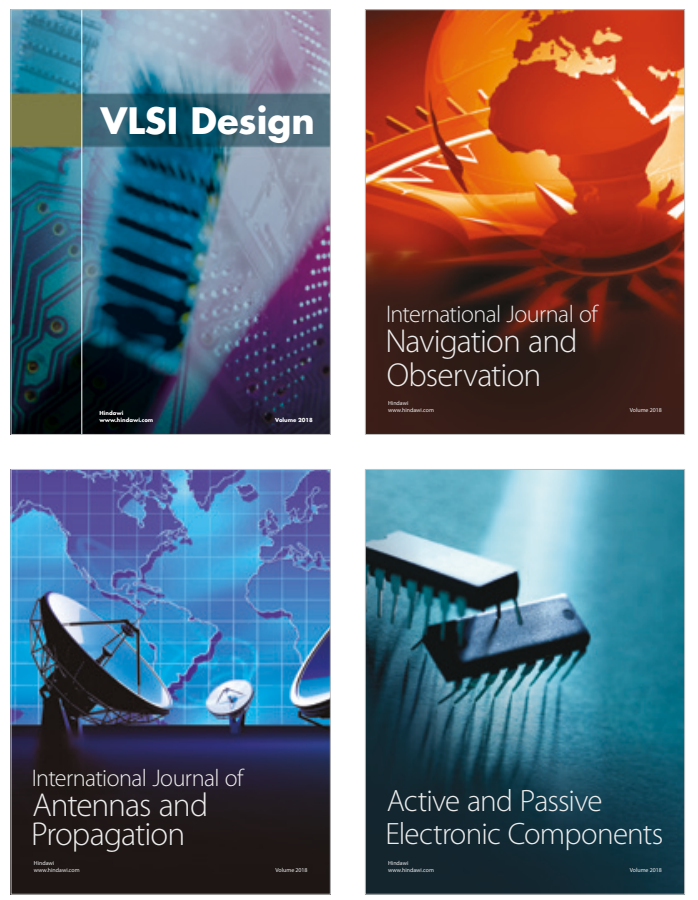
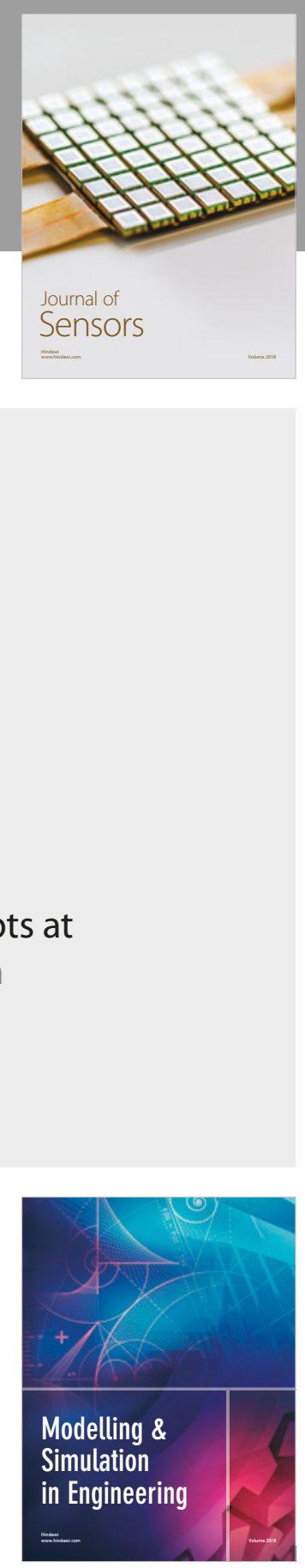

\section{Advances \\ Multimedia}
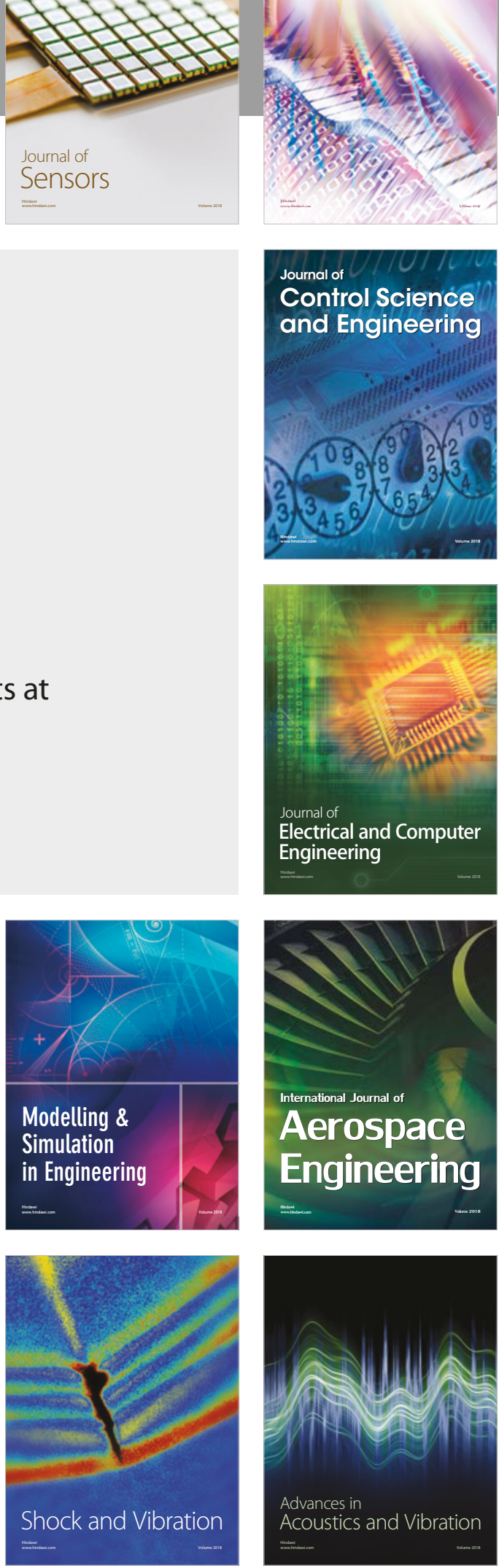